\title{
SERUM THYROID HORMONE PROFILE IN BREAST CANCER PATIENTS
}

\author{
Abdalla Mohammed Jarari1, Nouh M. H. AlJarari², Jagannadha Rao Peela 3 , Saeid Omer Alsoaeiti4, Hajar Yousef Ali ${ }^{5}$, \\ Aaren Vedangi ${ }^{6}$, Anuradha Argi 7 , Azhar Hussain ${ }^{8}$ \\ 1 Professor, Department of Biochemistry, Faculty of Medicine, Benghazi University, Benghazi, Libya. \\ ${ }^{2}$ Associate Professor, Department of Pharmacology, Faculty of Medicine, Benghazi University, Benghazi, Libya. \\ ${ }^{3}$ Associate Professor, Department of Biochemistry and Medical Genetics, St. Matthew's University School of Medicine, Cayman Islands. \\ 4 Professor, Department of Surgery, Faculty of Medicine, Benghazi University, Benghazi, Libya. \\ ${ }^{5}$ Tutor, Department of Biochemistry, Faculty of Medicine, Benghazi University, Benghazi, Libya. \\ ${ }^{6}$ Research Fellow, Triesta Sciences, HCG Pinnacle Oncology Hospitals Pvt. Ltd., Visakhapatnam, India. \\ ${ }^{7}$ Post-Doctoral Fellow, Department of Human Genetics, College of Science and Technology. Andhra University, Visakhapatnam, India. \\ ${ }^{8}$ Research Scholar, Department of Business Management, Davenport University College of Business Degrees. Michigan, U.S.A.
}

\section{MATERIALS AND METHODS}

This was a prospective observational study. Pre-treatment group consisted of breast cancer patients who at the initial time of diagnosis $(n=28)$, post-treatment group comprising of patients who had undergone either chemotherapy/ radiotherapy or hormone therapy for their disease $(n=37)$. The fibrocystic group comprising of patients with benign breast tumour $(n=21)$ and 51 healthy control group consisted of members of the public with no prior history of breast cancer or other cancer-related disorders ( $n=51$ ) were included in the study. Thyroid history was reported. Thyroid hormones (FT4, FT3, TSH, T3, T4) and thyroid antibodies (TPO. Ab and TG. Ab) were determined. The Kruskal-Wallis H and Mann-Whitney U tests ( $p<0.005$ significant) were used for statistical analysis.

\section{RESULTS}

Free thyroxine measurements showed significant difference comparing both CA breast patients, pre-treatment $(p=0.009)$ and post-treatment $(p=0.001)$, respectively to the control group. There was no significant difference in free thyroxine levels between fibrocystic patients and control groups $(p=0.917)$ as well as a non-significant difference in free thyroxine levels was found between fibrocystic patients and post-treatment CA breast patients $(p=0.079)$. There was no significant difference in thyroxine (T4) measurement between breast cancer groups, fibrocystic group and normal healthy control group ( $p>0.05$ ). The free triiodothyronine (T3) measurements showed no significant difference between breast cancer groups, fibrocystic group and normal healthy control group ( $\mathrm{p}>0.05)$. The thyrotropin (TSH) measurements showed significant difference comparing both CA breast patients, pre-treatment $(\mathrm{p}=0.016)$ and post-treatment $(\mathrm{p}=0.01)$ respectively to the control group. The thyroid peroxidase antibodies (anti-TPO) measurements showed no significant difference between breast cancer groups, fibrocystic group and normal healthy control group $(\mathrm{p}>0.05)$.

\section{CONCLUSION}

The subclinical hypothyroidism was seen more frequently in breast cancer patients, changing levels of thyroid hormones suggested dysregulation in breast cancer patients. These data must be confirmed in large patient's prospective observational study.

\section{KEYWORDS}

Thyroid Hormone, Breast Cancer, Thyroxine, Kruskal-Wallis H, Mann-Whitney U and Triiodothyronine.

HOW TO CITE THIS ARTICLE: Jarari AM, AlJarari NMH, Peela JR et al. Serum thyroid hormone profile in breast cancer patients. J. Evolution Med. Dent. Sci. 2018;7(06):719-723, DOI: 10.14260/jemds/2018/163

\section{BACKGROUND}

Breast cancer is caused by the uncontrollable growth of new tissue that starts in a mammary gland and then spreads. ${ }^{1}$

'Financial or Other Competing Interest': None.

Submission 13-01-2018, Peer Review 25-01-2018,

Acceptance 27-01-2018, Published 05-02-2018.

Corresponding Author:

Dr. Jagannadha Rao Peela,

Department of Biochemistry and Medical Genetics,

School of Medicine, St. Matthew's University,

Leeward 3, Regatta Office Park,

Grand Cayman, Cayman Islands-KY1-1204.

E-mail: pjrao@stmatthews.edu

DOI: $10.14260 /$ jemds $/ 2018 / 163$

\section{(c) (i) $($ ) $\Theta$}

The World Health Organization (WHO) classifies breast cancer on the basis of its two origin sites; Types (I) Ductal and (II) Lobular. ${ }^{2}$ Ductal carcinoma constitutes $80 \%$ - 90\% and lobular carcinoma constitutes $10 \%-20 \%$ breast cancer. ${ }^{3}$ Breast cancer remains a major public health problem. The most common cancer worldwide and the second leading cause of cancer death. It also accounts for 23\% (1.38 million) of the total new cancer cases and $14 \%(458,400)$ of the total cancer deaths in 2008. The breast cancer ranks as the second most common cancer overall (10.9\% of all cancers), but ranks as the fifth most common cancer which can ultimately cause death. 4

It is today clear that cancer is caused by specific mutations in specific key regulatory genes. A range of risk 
factors has been identified including genetic, hormonal and lifestyle factors. The transformation of normal epithelium through carcinoma in situ to invasive malignancy is correlated with the altered gene expression, which results in alterations in biological pathways as well as with genetic changes such as mutation of specific genes and chromosomal aberrations. 5 The involvement of thyroid hormones in development and differentiation of normal breast tissue has been established, the coincidence of thyroid disease and breast cancer has long been a subject of debate. One of the earliest reports on the association of breast cancer with thyroid disease was in 1896, ${ }^{6}$ in which thyroid extract was used to treat breast cancer. In 1996, Smyth et al reported increased thyroid enlargement rate among breast cancer patients. ${ }^{7}$ Although, breast density is influenced by genetics, it is also affected by a number of other factors. In most women it will change over time, decreasing with age. ${ }^{8}$ Many genetic loci are known to contribute to the risk of familial breast cancer including highly penetrant deleterious germline mutations in the BRCA1 and BRCA2 tumour suppressor genes. BRCA1 and BRCA2 breast cancers are distinct in their expression of hormone receptors ${ }^{9}$ and p53 and PTEN. ${ }^{10}$ Environmental pollutants similar to hormones can also interfere in the control of a large family of nuclear hormone receptors, which in turn can up-regulate various genes involved in the cell cycle.11 These pollutants are designated xenoestrogens which include pesticides, dyes, food preservatives and other pollutants and can play a role in the aetiology of breast cancer since they interfere with the activity of endogenous oestrogens. ${ }^{12}$ The incidence of breast cancer was significantly higher among patients receiving thyroid hormone in comparison to control patients. The risk increased with duration of use, being almost $20 \%$ in those receiving it for more than 15 years. The risk was more than three-fold higher in nulliparous women receiving thyroid hormone, reaching 33\%, whereas it was only $9.25 \%$ in those not receiving thyroid hormone.

\section{MATERIALS AND METHODS}

In this prospective observational study patients with newly diagnosed breast cancer were included before surgery, chemotherapy, radiation or antihormonal therapy. The thyroid function was investigated in breast cancer patients and compared to patient's newly diagnosed breast cancer women with the fibrocystic disease and healthy controls.

A total of 86 Libyan women patients with various stages of breast tumour diseases were recruited from the 7 th October Hospital and Benghazi Medical Centre (BMC) for this study. These women were subdivided into pre-treatment group that consisted of 28 patients with breast cancer who are at the initial time of diagnosis $(n=28)$, post-treatment group comprising of 37 patients who had undergone either chemotherapy/ radiotherapy or hormone therapy for their disease $(n=37)$ and the fibrocystic group comprising of patients with benign breast tumour $(n=21)$. The healthy control group consisted of 51 members of the public with no prior history of breast cancer or other cancer-related disorders $(n=51)$ was also used for this study. Informed consent was obtained from all subjects before the study.

The serum free Triiodothyronine (T3), free thyroxine (T4) levels and serum thyrotropin (TSH) levels were measured using enzyme immunoassays. The normal ranges were 2.2 - $6.8 \mathrm{pmol} / \mathrm{L}$ for free T3, 12 - $22 \mathrm{pmol} \backslash \mathrm{L}$ for free T4 and $0.3-5.0 \mu \mathrm{IU} / \mathrm{mL}$ for TSH. All the patients underwent serological determination of thyroid auto-antibodies antiTPO. The auto-antibodies specific for thyroglobulin were also measured. The normal ranges were $0-60 \mathrm{IU} / \mathrm{mL}$ for antithyroglobulin antibodies and $0-20 \mathrm{IU} / \mathrm{mL}$ for anti-TPO antibodies. The Kolmogorov-Smirnov Goodness of fit test was used to control whether the distribution of parameters is within the normal distribution. The test showed that some of the parameters were not in the normal distribution. Thus, groups were compared with the KruskalWallis $\mathrm{H}$, followed by the Mann-Whitney $\mathrm{U}$ test for serum thyroid hormone and antibody levels. The data were then expressed as mean with standard deviation (SD).

\section{RESULTS}

The mean age and standard deviation (SD) of the patients with breast tumour diseases selected for this study were 43.9 \pm 13.1 , the age range was $20-70$ years. The mean age and SD of the healthy control subjects was $41.54 \pm 9.9$, the age range was 22 - 60 years. BMI was significantly higher in both groups, pre-treatment breast cancer group and posttreatment breast cancer group when compared to normal control $(\mathrm{p}<0.05)$, both of breast cancer pre-treatment and post-treatment groups were significantly different when compared with the fibrocystic group $(\mathrm{p}=0.003)(\mathrm{p}=0.000)$ respectively. Non-significant difference was found between the fibrocystic group and normal control group as well as between two pre-treatment and post-treatment breast cancer groups.

\begin{tabular}{|c|c|c|c|c|}
\hline \multirow{2}{*}{ Parameter } & \multicolumn{4}{|c|}{ Patient's Groups } \\
\cline { 2 - 5 } & $\begin{array}{c}\text { Post- } \\
\text { Treatment } \\
(\mathbf{N}=37)\end{array}$ & $\begin{array}{c}\text { Pre- } \\
\text { Treatment } \\
(\mathbf{N = 2 8})\end{array}$ & $\begin{array}{c}\text { Fibrocystic } \\
\text { (N=21) }\end{array}$ & $\begin{array}{c}\text { Control } \\
(\mathbf{N = 5 1 )}\end{array}$ \\
\hline $\begin{array}{c}\text { BMI } \\
\left(\mathrm{kgm}^{-2}\right)\end{array}$ & $31.1 \pm 5.1^{*}$ & $30.3 \pm 4.5^{*}$ & $26.7 \pm 4.9^{*}$ & $27.0 \pm 2.3$ \\
\hline $\begin{array}{c}\mathrm{T} 3 \\
(\mathrm{nmol} / \mathrm{L})\end{array}$ & $2.23 \pm 0.5^{\mathrm{NS}}$ & $2.13 \pm 0.4^{\mathrm{NS}}$ & $2.23 \pm 0.4^{\mathrm{NS}}$ & $2.02 \pm 0.3$ \\
\hline $\begin{array}{c}\mathrm{FT} 3 \\
(\mathrm{pmol} / \mathrm{L})\end{array}$ & $5.8 \pm 0.9^{\mathrm{NS}}$ & $6.1 \pm 1.2^{\mathrm{NS}}$ & $6.2 \pm 0.8^{\mathrm{NS}}$ & $5.7 \pm 0.8$ \\
\hline $\begin{array}{c}\mathrm{FT} 4 \\
(\mathrm{pmol} / \mathrm{L})\end{array}$ & $16.3 \pm 3.2^{*}$ & $15.6 \pm 4.1^{*}$ & $17.7 \pm 2.8^{\mathrm{NS}}$ & $18.1 \pm 3.3$ \\
\hline $\begin{array}{c}\mathrm{T} 4 \\
(\mathrm{nmol} / \mathrm{L})\end{array}$ & $118 \pm 14.2^{\mathrm{NS}}$ & $115 \pm 12.5^{\mathrm{NS}}$ & $120 \pm 9.2^{\mathrm{NS}}$ & $114.3 \pm 10.9$ \\
\hline $\begin{array}{c}\mathrm{TSH} \\
(\mu \mathrm{IU} / \mathrm{mL})\end{array}$ & $2.03 \pm 0.4^{*}$ & $2.1 \pm 0.5^{*}$ & $1.8 \pm 0.48^{\mathrm{NS}}$ & $1.8 \pm 0.4$ \\
\hline $\begin{array}{c}\mathrm{Anti}-\mathrm{TG} \\
(\mathrm{IU} / \mathrm{mL})\end{array}$ & $24.2 \pm 8.13^{\mathrm{NS}}$ & $21.6 \pm 7.4^{\mathrm{NS}}$ & $23.2 \pm 7.2^{\mathrm{NS}}$ & $20.1 \pm 16.7$ \\
\hline $\begin{array}{c}\mathrm{Anti}-\mathrm{TPO} \\
(\mathrm{IU} / \mathrm{mL})\end{array}$ & $15.3 \pm 6.0^{\mathrm{NS}}$ & $17.4 \pm 6.5^{\mathrm{NS}}$ & $16.7 \pm 5.8^{\mathrm{NS}}$ & $17.2 \pm 5.1$ \\
\hline \multicolumn{4}{|c|}{ Table 1 } \\
\hline
\end{tabular}

NS= Not Significant, ${ }^{*}$ P value $<0.005$

Table 1: Mean \pm SD of Body Mass Index (BMI), Triiodothyronine ( $\left.\mathrm{T}_{3}\right)$, Free thyroxine (FT4), Free Triiodothyronine, Thyrotropin (TSH), Thyroglobulin antibodies (Anti-TG) and Anti-thyroid peroxidase antibodies (Anti-TPO) in post-treatment breast, pre-treatment breast cancer patients, fibrocystic patients and healthy control subjects. Post-treatment CA breast refers to the breast cancer patients who had undergone chemotherapy/ radiotherapy or hormone therapy or mastectomy for their disease. Pre- 
treatment CA breast refers to the breast cancer patients who are at the time of diagnosis. Fibrocystic patients are the patients with benign breast tumour. The control are the normal healthy subjects.

The T3 measurement showed no significant difference between breast cancer groups, fibrocystic group and normal healthy control group ( $p>0.05)$. Free thyroxine measurements showed significant difference comparing both the CA breast patients pre-treatment $(p=0.009)$ and the posttreatment $(p=0.001)$ respectively to the control group. The non-significant difference in free thyroxine levels was found between the fibrocystic patients and the control groups $(p=0.917)$. There was a non-significant difference seen in free thyroxine levels between the fibrocystic patients and the post-treatment CA breast patients $(p=0.079)$ as well as between the fibrocystic patients and the pre-treatment CA breast patients $(p=0.066)$. There was a non-significant difference found in free thyroxine measurements between the pre-treatment CA breast patients and the post-treatment CA breast patients $(p=0.419)$. The thyroxine (T4) measurements showed no significant difference between the breast cancer groups, fibrocystic group and the normal healthy control group ( $p>0.05)$. The free Triiodothyronine T3 measurements showed no significant difference between the breast cancer groups, fibrocystic group and the normal healthy control group ( $p>0.05)$. However, thyrotropin (TSH) measurements showed significant difference comparing both the CA breast patients pre-treatment $(\mathrm{p}=0.016)$ and the posttreatment $(\mathrm{p}=0.01)$ respectively to the control group. There was no significant difference when compared both the CA breast patients pre-treatment $(p=0.110)$ and the posttreatment $(p=0.069)$ respectively to the fibrocystic group. The TSH measurements showed no significant difference between the fibrocystic patients $(p=0.837)$ to the control group. There was a non-significant difference found in the TSH measurements between the pre-treatment CA breast patients and the post-treatment CA breast patients $(\mathrm{p}=0.809)$. The thyroid peroxidase antibodies (anti-TPO) measurement showed no significant difference between the breast cancer groups, fibrocystic group and the normal healthy control group $(\mathrm{p}>0.05)$.

\section{DISCUSSION}

The breast cancer is a hormone-dependent neoplasm. ${ }^{13}$ The conflicting results regarding the clinical correlation between the breast cancer and the thyroid diseases have been reported in the previous literature. There are numerous studies showing the thyroid diseases are common among women with breast cancer, ${ }^{14}$ whereas other reports did not confirm such an association of breast cancer with the thyroid diseases, 15 and this includes almost every form of thyroid disease including nodular hyperplasia. This prospective observational study confirmed the presence of differences in the serum thyroid hormones and the thyroid antibodies levels, between the patients with breast cancer who underwent several types of therapy, the patients with breast cancer at initial diagnosis and the fibrocystic disease patients in comparison to control women.

The TSH is the most important thyroid hormone for diagnosis of hypothyroidism as well as hyperthyroidism. ${ }^{16}$ The serum levels of TSH above $3.5 \mathrm{~mL} / \mathrm{L}$ were observed in $21.6 \%$ of women with the CA breast and $7.1 \%$ of women with the CA breast (at time of diagnosis) and $0 \%$ of women with the fibrocystic disease compared to $15.3 \%$ of women from the control group. The mean TSH values were within the normal range. However, certain studies showed the increased TSH serum levels and hypothyroidism in breast cancer patients. ${ }^{17,18}$ This is inconsistent with the data provided by other studies that did not demonstrate differences in TSH values between the breast cancer patients. ${ }^{19,20}$ In a previous study (5.4\%) breast cancer patients had elevated both the serum values of TSH and the TPO. Ab. The serum levels of TPO. Ab and the TG. Ab did not differ significantly between the individual's groups $(p>0.05)$. The study did not confirm recent reports of higher TPO. Ab in women with the breast carcinomas. ${ }^{21}$

In this study, the serum levels of FT3 which were not elevated significantly in the breast diseases patients (posttreatment CA breast, pre-treatment CA breast and fibrocystic disease) compared to control ( $p>0.05$ ). There were nonsignificant differences between the breast cancer disease groups when compared altogether. Some studies showed significantly higher FT3 in breast cancer patients than the controls, whereas this change is not seen in this study. ${ }^{18,22}$ Many studies showed the non-significant differences between the breast cancer patients and the control group in mean serum FT3 levels. ${ }^{23,24,25}$

The serum free thyroxine (FT4) was significantly lower in the breast cancer patients when compared to the controls $(p<0.05)$. There was no significant difference found between the pre-treatment CA breast, the fibrocystic disease patients and the controls $(p>0.05)$. There was also a non-significant difference in FT4 level between the breast diseases groups when compared together. In confirmation of these findings with Kuijpens et al showed a significantly lower level of serum FT4 in the breast cancer patients (2775) when compared to the women without the breast cancer. ${ }^{19}$ Saraiva et al showed a significantly higher level of FT4 in postmenopausal women CA breast patients compared to the women without the breast cancer. ${ }^{21}$ In 2010, Ditsch et al showed a significantly higher level of serum FT4 breast cancer women when compared to control as well as to the patients with the benign breast tumour $(\mathrm{p}>0.05) .{ }^{18}$

The serum thyroxine T4 level showed no significant difference between the respective groups in the present study ( $p>0.05)$. The serum triiodothyronine T3 was significantly higher in the breast cancer post-treatment patients compared to the controls. There was no significant difference found between the respective groups in this study when compared together. Some studies demonstrated that there was a decrease in thyroid hormone function in Breast cancer patients after treatment with chemotherapy, hormonal therapy, surgery or radiation therapy. ${ }^{26}$ It appears that the multiple therapies may influence the development of thyroid dysfunction via disturbances of the auto-immune system. ${ }^{27}$ However, this study shows that there was no significant influence of therapy on the parameters of thyroid function when compared to the pre-treatment breast cancer to the post-treatment cancer patients.

The involvement of thyroid hormone in the development and differentiation of normal breast tissue has been established. 16 The T3 regulates growth hormones metabolism and since the differentiation of $\mathrm{T} 3$ has an oestrogen-like effect; therefore, the T3 possibly acts like oestrogen 
effector.28,29 In addition investigators found that triiodothyronine (T3) actions are mediated by specific highaffinity nuclear receptors (TR), which are encoded by two genes, TR $\alpha$ and TR $\beta$ [24]. Recent results revealed that the substantial changes in the expression profile of TH receptors suggesting a possible dysregulation that could trigger the breast cancer development. 30

Some research studies on the breast cancer cell line demonstrated that the T3 mimicked the effects of estradiol (E2). ${ }^{28,31}$ In addition, T3 effects were antagonised by the simultaneous addition of Tamoxifen (TAM), which is a competitive inhibitor of E2 binding to the ER. Such effects, however, were not observed in the ER-negative breast cancer cell. Dinda et al found in ER-positive breast cancer cells, the $\mathrm{T} 3$ regulates cell cycle progression and the proliferation which increases the expression of p53 and causing hyperphosphorylation of $\mathrm{pRb}$ by a common mechanism involving the ER and the T3 receptor (T3R)-mediated. ${ }^{31}$ There are certain studies that demonstrate the existence of specific alterations in $\operatorname{TR} \alpha$ and $\operatorname{TR} \beta$ gene expression and suggesting that the dysregulation of the target genes and transcription of the thyroid hormones could be implicated in the genesis of these neoplasias. $28,30,31$

The future studies are needed that should focus on the thyroid receptors and its impact in order to specify the role in the breast cancer patients and highlight possible influences on cancer outgrowth and the progression. Consequently, it may become a targeted receptor for hormonal therapy. ${ }^{31}$

\section{CONCLUSION}

The subclinical hypothyroidism is seen more frequently in the breast cancer patients. The levels of thyroid hormones suggest the dysregulation in breast cancer patients. The limitations of our study have not been based on the evaluated ultrasounds, Fine Needle Aspiration (FNA) and other clinical diagnoses of the thyroid gland. Therefore, the study does not identify whether the thyroid gland has any defect in patients. However, these data must be confirmed in the large patient's prospective observational study. Patients with breast cancer should be monitoring thyroid functions before and throughout the treatment period.

\section{ACKNOWLEDGEMENT}

Our sincere thanks to the academic staffs and technical staffs of Department of Biochemistry, Faculty of Medicine, University of Benghazi, Benghazi, Libya. Thanks to Doctors and paramedical staffs of Department of Surgery, Benghazi Medical Centre for providing patient data and samples. Our sincere thanks to the NASR, Tripoli, Libya for providing support to this project.

\section{REFERENCES}

[1] Recurrent non-metastatic breast cancer. National Center for Biotechnology Information. U.S. National Library of $\quad 2017$. https://www.ncbi.nlm.nih.gov/pubmedhealth/PMH0 072608/

[2] Makki J. Diversity of breast carcinoma: histological subtypes and clinical relevance. Clinical Medicine Insights: Pathology 2015;8:23-31.
[3] Sarkar S, Mandal M. Breast cancer: classification based on molecular etiology influencing prognosis and prediction. In Tech Open 2011. https://www.intechopen.com/books/breast-cancerfocusing-tumor-microenvironment-stem-cells-andmetastasis/breast-cancer-classification-based-onmolecular-etiology-influencing-prognosis-andprediction

[4] Ferlay J, Shin HR, Bray F, et al. Estimates of worldwide burden of cancer in 2008: GLOBOCAN 2008. International Journal of Cancer 2010;127(12):2893917.

[5] Becker M, Sommer A, Krätzschmar JR, et al. Distinct gene expression patterns in a tamoxifen-sensitive human mammary carcinoma xenograft and its tamoxifen-resistant subline MaCa 3366/TAM. Molecular Cancer Therapeutics 2005;4(1):151-68.

[6] Beatson GT. On the treatment of inoperable cases of carcinoma of the mamma: suggestions for a new method of treatment with illustrative cases. Lancet 1896;148(3803):162-5.

https://www.popline.org/node/475675

[7] Smyth PP, Smith DF, McDermott EW, et al. A direct relationship between thyroid enlargement and breast cancer. The Journal of Clinical Endocrinology and Metabolism 1996;81(3):937-41.

[8] Boyd N, Martin L, Stone J, et al. A longitudinal study of the effects of menopause on mammographic features. Cancer Epidemiology, Biomarkers \& Prevention 2002;11(10 Pt 1):1048-53.

[9] Karp SE, Tonin PN, Bégin LR, et al. Influence of BRCA1 mutations on nuclear grade and estrogen receptor status of breast carcinoma in Ashkenazi Jewish women. Cancer 1997;80(3):435-41.

[10] Borwell B, Rowlings B. Bowel cancer: foundations for practice. London: Whurr 2005.

[11] Maruchi N, Annegers JF, Kurland LT. Hashimoto's thyroiditis and breast cancer. Mayo Clinic proceedings 1976;51(5):263-5.

[12] Garner CE, Matthews HB, Burka LT. Phenolphthalein metabolite inhibits catechol-0-methyltransferasemediated metabolism of catechol estrogens: a possible mechanism for carcinogenicity. Toxicology and Applied Pharmacology 2000;162(2):124-31.

[13] Ruiz-Cabello J, Berghmans K, Kaplan 0, et al. Hormone dependence of breast cancer cells and the effects of tamoxifen and estrogen: 31P NMR studies. Breast Cancer Research and Treatment 1995;33(3):209-17.

[14] Shering SG, Zbar AP, Moriarty M, et al. Thyroid disorders and breast cancer. European Journal of Cancer Prevention 1996;5(6):504-6.

[15] Límanová Z, Barkmanová J, Friedmanová Z. Frequent incidence of thyropathies in women with breast carcinoma. Vnitrni Lekarstvi 1998;44(2):76-82.

[16] Carvalho GA, Perez CLS, Ward LS. The clinical use of thyroid function tests. Arquivos Brasileiros de Endocrinologia \& Metabologia 2013;57(3):193-204.

[17] Jiskra J, Límanová Z, Barkmanová J, et al. Autoimmune thyroid diseases in women with breast cancer and colorectal cancer. Physiological Research 2004;53(6):693-702. 
[18] Ditsch N, Liebhardt S, Von Koch F, et al. Thyroid function in breast cancer patients. Anticancer Res 2010;30(5):1713-7.

[19] Kuijpens JL, Nyklíctek I, Louwman MW, et al. Hypothyroidism might be related to breast cancer in post-menopausal women. Thyroid 2005;15(11):12539.

[20] Dulger H, Alici S, Algun E, et al. Antithyroid antibody levels in patients with breast cancer. European Journal of General Medicine 2004;1(2):11-14. http://dergipark.ulakbim.gov.tr/ejgm/article/view/5 000115205

[21] Saraiva PP, Figueiredo NB, Padovani CR, et al. Profile of thyroid hormones in breast cancer patients. Brazilian Journal of Medical and Biological Research 2005;38(5):761-5.

[22] Turken O, NarIn Y, DemIrbas S, et al. Breast cancer in association with thyroid disorders. Breast Cancer Research 2003;5(5):R110-3.

[23] Giani C, Fierabracci P, Bonacci R, et al. Relationship between breast cancer and thyroid disease: relevance of autoimmune thyroid disorders in breast malignancy. The Journal of Clinical Endocrinology and Metabolism 1996;81(3):990-4.

[24] Szychta PC, Szychta W, Gesing A, et al. TSH receptor antibodies have predictive value for breast cancer retrospective analysis. Thyroid Research 2013;6(1):8.

[25] Farahati J, Roggenbuck D, Gilman E, et al. Anti-thyroid peroxidase antibodies are associated with the absence of distant metastases in patients with newly diagnosed breast cancer. Clinical Chemistry and Laboratory Medicine 2012;50(4):709-14.
[26] Huang J, Jin L, Ji G, et al. Implication from thyroid function decreasing during chemotherapy in breast cancer patients: chemosensitization role of triiodothyronine. BMC Cancer 2013;13:334.

[27] Barbesino G, Chiovato L. The genetics of Hashimoto's disease. Endocrinology and Metabolism Clinics of North America 2000;29(2):357-74. http://www.sciencedirect.com/science/article/pii/S0 889852905701365

[28] Rasool M, Naseer MI, Zaigham K, et al. Comparative study of alterations in Tri-iodothyronine (T3) and Thyroxine (T4) hormone levels in breast and ovarian cancer. Pakistan Journal of Medical Sciences 2014;30(6):1356-60.

[29] González-Sancho JM, García V, Bonilla F, et al. Thyroid hormone receptors/THR genes in human cancer. Cancer Letters 2003;192(2):121-32.

[30] Conde I, Paniagua R, Zamora J, et al. Influence of thyroid hormone receptors on breast cancer cell proliferation. Annals of Oncology 2006;17(1):60-4.

[31] Dinda S, Sanchez A, Moudgil V. Estrogen-like effects of thyroid hormone on the regulation of tumor suppressor proteins, p53 and retinoblastoma, in breast cancer cells. Oncogene 2002;21(5):761-8. 